\title{
HVMANITAS
}

\section{O percurso de Pedro João Perpinhão, em Portugal}

\section{Autor(es): $\quad$ Toipa, Helena Costa}

Publicado por: $\begin{aligned} & \text { Faculdade de Letras da Universidade de Coimbra, Instituto de Estudos } \\ & \text { Clássicos }\end{aligned}$

URL

persistente:

DOI: $\quad$ DOI:http://dx.doi.org/10.14195/2183-1718_63_23

Accessed : $\quad$ 26-Apr-2023 15:18:20

A navegação consulta e descarregamento dos títulos inseridos nas Bibliotecas Digitais UC Digitalis, UC Pombalina e UC Impactum, pressupõem a aceitação plena e sem reservas dos Termos e Condições de Uso destas Bibliotecas Digitais, disponíveis em https://digitalis.uc.pt/pt-pt/termos.

Conforme exposto nos referidos Termos e Condições de Uso, o descarregamento de títulos de acesso restrito requer uma licença válida de autorização devendo o utilizador aceder ao(s) documento(s) a partir de um endereço de IP da instituição detentora da supramencionada licença.

Ao utilizador é apenas permitido o descarregamento para uso pessoal, pelo que o emprego do(s) título(s) descarregado(s) para outro fim, designadamente comercial, carece de autorização do respetivo autor ou editor da obra.

$\mathrm{Na}$ medida em que todas as obras da UC Digitalis se encontram protegidas pelo Código do Direito de Autor e Direitos Conexos e demais legislação aplicável, toda a cópia, parcial ou total, deste documento, nos casos em que é legalmente admitida, deverá conter ou fazer-se acompanhar por este aviso. 
humanitas

Vol. LXIII

2011 


\title{
O PERCURSO DE PEDRO JOÃO PERPINHÃO, EM PORTUGAL
}

\author{
Helena Costa Toipa \\ Centro de Estudos Clássicos e Humanísticos \\ Universidade de Coimbra/FCT
}

\begin{abstract}
Resumo
O padre jesuíta Pedro João Perpinhão viveu em Portugal, entre 1551 e 1561, e aqui desenvolveu intensa actividade de orador, professor e investigador. $\mathrm{O}$ seu percurso e actividade literária, neste período, estão documentados na epistolografia da Companhia de Jesus e na sua própria obra.

Palavras-chave: Pedro João Perpinhão, Companhia de Jesus, Colégio das Artes, Rainha Santa Isabel.
\end{abstract}

\begin{abstract}
The Jesuit priest Pedro João Perpinhão lived in Portugal, from 1551 to 1561, and here he worked hard as a public speaker, teacher and investigator. His life and literary activity, during this period, are documented on the epistolography of the Society of Jesus and on his own works.

Key-words: Pedro João Perpinhão, Society of Jesus, Colégio das Artes, Queen Saint Elizabeth.

\section{1 - Percurso biográfico}

Pedro João Perpinhão nasceu em Elche, na região de Valência, em território aragonês, em 1530, e morreu, em Paris, passados 36 anos de uma vida inteiramente dedicada ao estudo, à docência, à oratória e à investigação, 15 dos quais ao serviço da Companhia de Jesus. Na sua actividade,
\end{abstract}


percorreu Espanha, Portugal, Itália e França. Se o seu périplo não foi tão alargado como o dos seus companheiros missionários, cuja actividade se estendeu por vários continentes e que foram até às longínquas paragens da Índia, do Japão, da China, do Brasil, em condições dificílimas e frequentemente com risco das próprias vidas, não deixou de servir a Companhia com igual intensidade e espírito de sacrifício e renúncia, trabalhando e penitenciando-se de tal forma, que o seu corpo, debilitado, acabaria por sucumbir precocemente.

Ingressou na Companhia em 1551, depois de completar os seus estudos. Estudara primeiro em Orihuela e depois em Valência onde se graduou em Artes, a seis de Julho de $1547^{1}$. Dos seus antigos professores de Orihuela guardava, ao que parece, poucas saudades e a eles se refere num tom depreciativo. Em Valência, porém, a situação parece ter melhorado, pois na Universidade local, onde estudou filosofia e doutrina teológica, encontrou alguns professores que sobre ele exerceram uma influência decisiva para o seu futuro, nomeadamente para a sua eloquência, que viria a ser definitivamente marcada pelo cunho ciceroniano:

Caíra eu, ainda adolescente, nas mãos de mestres não muito bons e, enganado por eles, fui levado a ler e a imitar aqueles autores que ninguém quereria igualar, a não ser que fosse completamente estulto; então, ainda que me afastasse do caminho correcto, trabalhava tanto quanto me permitia aquela idade. A verdade, porém, é que me afastava, de dia para dia, para muito longe daquele objectivo que me propusera a mim próprio, até que, reconhecendo o erro, regressei ao caminho e converti todo o meu zelo em ler e conhecer completamente Cícero ${ }^{2}$, e, então, comecei a perceber o que

${ }^{1}$ Esta indicação é facultada por Fuster, Biblioteca de los escritores que florecieron hasta nuestros días. T. I, p. 309:

"Pedro Perpiñá, natural de Elche, que estudió aquí [Valentiae] seis cursos, se graduó de Bachiller en artes, en 6 de Julio de 1547, siendo su padrino Pedro Juan Monzó, asistiendo por examinadores Luis Juan Gensor, Jaime Nogueroles, Miguel Juan Luviela y Andrés Tarazona."

(citado em MHSI, Epistolae Mixtae, Tomo II, p. 200, numa carta de Andrés de Oviedo dirigida a João de Polanco, secretário de Inácio de Loyola, datada de Gandia, 8 de Maio de 1549.)

${ }^{2} \mathrm{O}$ seu gosto e admiração por Cícero levaram-no a tornar-se um excelente ciceroniano, fiel ao modelo e exprimindo constantemente a sua admiração incondicional, como na epístola a Francisco Adorno (Perpiniani, Opera, III, Epis. XVI). 
era falar de forma harmoniosa e ornada; finalmente, contemplei aquela primeira face da Eloquência, não a escondida pelos pigmentos e tintas pueris, mas a verdadeira, aquela cheia de suco natural e florescente graças à sua própria cor." 3

Aos 21 anos, entusiasmado provavelmente com o exemplo de alguns padres jesuítas do Colégio de Valência (fundado em 1544) que estudavam na Universidade, resolveu ingressar, então, na Companhia (Gaudeau 1891:10). Recebido pelos responsáveis Diogo Mirão e Jerónimo Domenech, foi enviado, em 1551, para o Colégio de Jesus de Coimbra, onde chegou em finais de Setembro, na companhia do irmão, Luís Perpinhão ${ }^{4}$.

Baltazar Telles, um dos historiadores da Companhia, exprime-se nestes termos, referindo-se a Perpinhão:

"(...) famoso orador naquelles tempos, como adiante veremos, porque nelle se viam, em grao muito superior, todas as partes por onde Cicero definia a hum perfeito Orador, porque as palavras eram muito boas, as sentenças bem accomodadas, a pronunciaçam excellente, a voz, o rosto, o gesto, o meneo, tudo muy engraçado, e bem proporcionado."

(Crónica da Companhia de Jesus na Província de Portugal, II Parte, Lib IV, p.19)

${ }^{3}$ Incideram ego adolescens in non optimos magistros, a quibus deceptus contuli me ad eos legendos et imitandos, quorum similis nemo, nisi sit omnino stultus, esse uelit: ibi cum de recto tramite deflexissem, laborabam quantum illa ferebat aetas: uerum ab eo quod mihi proposueram longius in dies discedebam, tandem errore cognito redii in uiam, omne meum studium ad legendum Ciceronem et cognoscendum penitus conuerti, tum demum intelligere coepi, quid sit composite et ornate loqui, tum primam illam Eloquentiae non pigmentis oblitam fucoque puerili, sed ueram, sed naturalis succi plenam, et suo colore florentem faciem aspexi.

(Oratio Ad Romanam iuuentutem de auita dicendi laude recuperanda dita em Roma, em 1564)

${ }^{4}$ Em carta datada de 23 de Fevereiro de 1562, escrita de Braga para o P. Jerónimo Nadal, o P. Diego Alvarez de Cisneros, ao falar das dificuldades que ocorriam, no colégio da Companhia dessa cidade, no uso da língua latina, fala do P. Luís e o editor diz, em nota:

Ludovicus Perpiñá, (apud castellanos, Perpiñán) frater egregii oratoris Petri Perpiñá.(...). En nonnulla illius examinum excerpta. Exam. comm. "Llámome Lluis Perpiñán. 2. Tengo 32 años y medio. 3. Soy del reyno de Valencia, de la villa de Elche (...) 10. Siempre de pequeño e estudiado, y aprendía á canto llano y de huérgano (...) 16. A que estoy en la Compañía diez años (...) 22. 
Da sua passagem de Valência, onde ingressara na Companhia, para Coimbra, testemunha uma carta do P. Hieronymus Domenech a Inácio de Loyola, escrita em 31 de Dezembro de 1551, de Gandia:

"Partido que fué el P. Miron, plugo al Señor mover cuatro estudiantes valencianos para entrar en la Compañia; los tres teólogos y el otro que habia ya acabado su curso de artes; mancebos hábiles y de los cuales en el estudio se tenía muy buena expectation. No pudiendo enviarlos á V. R., como deseabamos, com algunos otros de acá y de Gandía, los enviamos con el hermano Xaravia á Portugal, pidiéndolo ellos com instancia por la persecucion que temian que acá les dieran los suyos. Porque dos de ellos, que eran hermanos, llamados los Perpinyanes, y outro llamado Marcos Pancrudo, tienen madres viudas y ricas, y temian que no lo sintiesen mucho, como de verdad lo han sentido mucho. Mas plugo al Señor que, volviendo el hermano Xaravia, habiéndolos dejado en el Colegio de Coimbra muy buenos y consolados, fuese á visitar las madres trayéndoles cartas de sus hijos, la una á media jornada de aquí, la outra á dos y media, que se aconsolasen tanto, que dijesen estar muy contentas y hacer gracias á Nuestro Señor por el beneficio grande que hacia á sus hijos de quererse servir de ellos, rogándonos mucho que sus casas tomemos por propias, que en el mismo lugar nos tendrán como á sus hijos, deseando mucho que por alla fuésemos para aprovecharse en sus espíritus."

(MHSI, Litterae Quadrimestres, Tomo I, pp. 465-466)

Tengo órdenes de missa. 23. Primero estuve en Coimbra entendiendo en officios algún tiempo; después estudié algunos meses theología y casos de conscientia. Acompanyé al Padre doctor á Lixboa quando fué lo del Padre maestre Simón, y allí lo serví algun tiempo: después torné á Coimbra, donde torné á officios, y después algunos meses á la theología y algunos casos. Mandáronme á Lisboa, donde tomé órdenes y confessé estudiantes. De allí á un tiempo me hizieron ministro, y lo fuí serca dos anyos. Mandáronme á Coimbra para acabar de oir theología, donde estuve un mês esperando que passasen las ferias; y antes que acabasen de pasar, me tornaron al oficio de ministro, donde estuve pasante 4 años, y agora ará dos que me mandaron acá para lo mismo." Examen pro scholasticis. "1 ...e estudiado latín ....y artes antes que entrase en la Compañia en Valencia, y la theología en Coimbra..." Ex. Cod. 16, IV, 538, 539.

(MHSI, Epist. P. Nadal, Tomo I, pp. 658-659) 
Em Coimbra esteve dois anos, a fazer o noviciado, de acordo com as normas da Companhia. ${ }^{5}$ Em 1553, mudou-se para Évora. Da sua ida de Coimbra para Évora, passando por Lisboa, dão notícia algumas cartas datadas desse período. Numa carta para Inácio de Loyola, datada de Lisboa de 11 de Julho de 1553, diz Pedro de Santa Cruz:

"Los dias pasados pasaron por aquí cuatro Maestros de Coimbra para Évora, los tres para leer humanidad, scilicet, Pero Perpiñan, valentiano, Marcos Nuñez y Nuñalvarez, portugueses, Marcos Jorge para leer casos de conciencia y él es portugués. Espérase también allá mucho fruto en lo uno y en lo outro. Nuestro Señor lo aumente para su santo servicio."

(MHSI, Litterae Quadrimestres, Tomo II, pág. 352)

${ }^{5}$ Dessa passagem por Coimbra guardava boas recordações, como revela em carta (Opera, III, Epist. XVI) a Francisco Adorno, o genovês que ali tivera por companheiro, e que, depois, foi secretário e amigo do Cardeal Carlos Borromeu:

Memini profecto, memini temporis illius, quo mihi tempore felicius aliud nullum tempus illuxit, cum in illa Conimbricensi pietatis officina ad omnia tum priuatae tum publicae uirtutis officia quasi denuo fingebamur, et a Deo magistro per optimos religiosissimosque Patres praeceptis salutaribus conformabamur, cum illa quae nunc plerisque, ac mihi etiam ipsi, magis quam aliis, uideo difficilia atque aspera uideri et alia longe maiora, nemine uel imperante uel monente, sponte nostra, uel diuino potius quodam impulsu faciebamus. Quamquam ego spectator magis eram alienarum uirtutum quam auctor mearum. Sed illa ipsa certe multorum egregie factorum contemplatio, quamuis ipse ab illa perfecti officii ratione longius abessem, et magna me uoluptate perfundebat, et studium melius instituendae uitae mirandum in modum inflammabat, et ad aliquid audendum maiores mihi animos addebat.

Lembro-me, sem dúvida, lembro-me bem daquele tempo (mais feliz do que esse nunca para mim brilhou nenhum outro), quando, naquela oficina de piedade conimbricense, éramos como que, de novo, modelados para todos os ofícios da virtude, quer privada quer pública, e éramos instruídos naqueles salutares preceitos por Deus pai, pelos excelentes e religiosíssimos padres, e (lembro-me) quando fazíamos aquilo que agora a muitos e a mim próprio também, mais do que aos outros, vejo parecer duro, e ainda muito mais importante, sem ninguém nos mandar ou aconselhar, de nossa livre vontade, quiçá, por qualquer impulso divino. Ainda que eu fosse mais espectador das virtudes alheias que autor das minhas. Mas pelo menos, essa mesma contemplação de muitos feitos egrégios, embora eu próprio estivesse muito longe dessa via do perfeito dever, não só me inundava de enorme prazer, como também inflamava, de modo admirável, o zelo de melhor orientar a minha vida, como ainda me acrescentava maior coragem para ousar algo. 
Numa outra carta, também dirigida ao fundador, o P. Melchior Cotta dá conta da mesma ocorrência, escrevendo de Coimbra, a 31 de Agosto de 1553:

"Los días pasados nos visitó y consoló mucho en el Señor el P. Maestro Miron, aunque no se detuvo por muchos dias por ser necesario dar principio á las escuelas en el Colegio de Évora; y ansí se partió de este Colegio en el fin de Junio llevando consigo cinco Hermanos, dos Sacerdotes y dos otros leigos, habiendo ya enviado adelante otros dos compañeros; y de estos fueron cuatro para leer, tres para leer latin, y outro casos de consciencia. El que há de leer rethórica se dice P. Perpiñan; los dos que han de leer gramática, uno se dice Nuño Alvarez y el outro Marcos Nuñez; para leer casos de consciencia fué el hermano Marcos Jorge.

(MHSI, Litterae Quadrimestres, Tomo II, pág. 371)

De Évora, onde Perpinhão leccionou retórica e grego, e onde deu mostras de grande obediência (vd. MHSI, Epistolae Mixtae, Tomo III, pág. 646) e zelo de virtude, escreve Miguel de Barros, em 1 de Setembro de 1553, para o mesmo destinatário, dando conta já do decorrer das aulas:

"En esta, que es de los 4 meses, daré cuenta brevemente á V. P. de lo de acá. Los hermanos, dia de decollation de S. Juan Baptista (que fué á 29 de Augusto), empeçaron sus lectiones públicas de grammática; la de los casos presto se empeçará; occupasse ahora el hermano, que los haa de leer, en unas conclusiones, que há de sustentar diante el Cardenal, poniendo alguas conclusiones de la theologia speculatiua y otras de la moral. El hermano que lee la Rhetorica ${ }^{6}$, tuuo por principio de las lecciones una oration en una de las classes, á do concurrieron muchos; y S. A., que tambien se quiso hallar presente, quedó muy contento asegun él dixo al P. Maestro Hierónymo Nadal, con el qual en esse dia concluyo algunas cosas acerca deste Collegio, consentiendo en lo que el p. le proponia."

(MHSI, Litterae Quadrimestres, Tomo II, págs. 380-381).

Foi Perpinhão que, em 28 de Agosto de 1553, fez a oração de sapiência na abertura do ano lectivo, em Évora, na presença de alunos e do Cardeal,

${ }^{6} \mathrm{O}$ editor da carta apresenta aqui, em rodapé, o seguinte esclarecimento:

Magister Petrus Perpignanus. Etc 
patrono do Colégio. Desse facto (e ainda do começo das aulas, no dia seguinte, do sucesso da escola, que levou a que, às três classes, se acrescentasse mais uma, chamando-se um outro professor para a leccionar) dá testemunho o P. Marco Jorge ao P. Inácio de Loyola, em carta de 1 de Janeiro de 1554:

No que diz respeito às aulas, tendes conhecimento, creio, de que modo, no dia passado de Santo Agostinho, foi pronunciada uma oração por um certo irmão, de nome Pedro Perpinhão, que ensina Retórica, na presença não só dos alunos e de uma grande quantidade de outras pessoas, mas também do Cardeal, com o maior aplauso de todos. No dia seguinte, começaram as explicações dos autores o os restantes exercícios do domínio das letras. Os professores agradam e, de dia para dia, aumenta o número de alunos; no momento presente, ultrapassam o número de 280. Cresce o número deles, tanto quanto, por mais longe, se torna mais conhecida a nossa escola e o modo de ensino; de forma que pareceu aos Padres Mestre Jerónimo Nadal e Mestre Mirão que não seriam suficientes as três classes de alunos que havia até agora, para além daquela em que se abordam casos de consciência, pelo que, decretaram acrescentar uma quarta e há-de ser chamado um professor para desempenhar essa tarefa. ${ }^{7}$

(MHSI, Litterae Quadrimestres, Tomo II, pág. 508)

Essa oração dita por Perpinhão é desconhecida, não aparecendo nas compilações das suas orações ou da sua obra em geral. Lazerus 1749: 33 34 diz que talvez o próprio Perpinhão, não a considerando perfeita, como

${ }^{7}$ Quodadscholaspertinet, cognitum,credo, habebis, quemadmodum die sancti Augustini transacto habita fuerit oratio a quodam fratre, cui Petro Perpiniano est nomen, qui rhetoricam profitetur, praesentibus non solum scholaribus et aliis quam plurimis, sed etiam Cardinale cum maximo omnium applausu. Sequenti die authorum enarrationes caeteraeque in litteris exercitationes coeptae sunt. Placent praeceptores, atque in dies shcolasticorum numerus augescit: in praesentiarum 280 numerum exsuperant; sic autem accrescit eorum numerus, quanto magis nostrum institutum et doctrinae modus latius innotescit, ut Patribus Magist. Hieronymo Natali et Magist. Myroni visum fuerit tres classes, quae hactenus scholasticorum erant, praeter eam, in qua de casibus conscientiae agebatur, non satis esse; quamobrem quartam addere decreuerunt, estque praeceptor ad id munus subeundum accersitus. 
primeiro fruto da sua eloquência, não tenha deixado que andasse juntamente com as outras.

Ali, em Évora, se manteve Perpinhão até 1555, ano em que a Companhia tomou conta do ensino do Colégio das Artes, em Coimbra, sendo aquele um dos escolhidos para ali leccionar. Era preciso impressionar os doutores de Coimbra e não fazer má figura, em comparação com os reputados mestres anteriores do Colégio. Por isso, para ali foram encaminhados Cipriano Soares, para a Retórica, Pedro Perpinhão e Manuel Álvares, para as duas classes de Latim.

Perpinhão era, pois, um dos melhores professores que a Companhia tinha em Portugal que, no geral, dispunha de muito poucos lentes; é constante, nas cartas enviadas para Roma, o pedido de mais docentes, que viessem obviar às falhas nítidas neste domínio. Ainda assim, porém, arranjaram-se alguns bons mestres, como dá conta Diogo Mirão, escrevendo a Inácio de Loyola, em Agosto de 1555, de Lisboa:

"También los que an de leer latín tienen muy grande exerçicio en hablar bien latín, y exerçítanse en leer agora en estas classes de Lixbona. Spero en nuestro Señor que lo harán mediocremente. Halámonos todauía faltos de leyentes notables, y speçialmente auiendo de succeder á los que dexan de leer, que son muy insignes. Cipriano leerá en la $\mathrm{I}^{\mathrm{a}}$, Pedro Perpiñan en la $2^{\mathrm{a}}$, Manuel Alvarez en la $3^{\mathrm{a}}$. Estos creo yo que darán mucha satisfaçión en el latin. Para la $4^{\mathrm{a}}$ y para la $5^{\mathrm{a}}$ tenemos á Miguel de Bairros y á Varea, el qual es aora prefecto aqui en Santo Antón. Para las otras tomaremos los más suffiçientes, de muchos que se preparan para leer. En las artes leerá el último y $4^{\circ}$ curso Jorge Serrano, el $3^{\circ}$ Fonsequa, el $2^{\circ}$ Ignatio Martinez, el $1^{\circ}$, que a de començar por Octobre, Marçal Vaz. Los dos primeros speramos que darán mucha satisfaçión. También se aparajen para ser maestros extrauagantes Sebastián de Moraes y Cardoso. Vista la falta que teníamos acá de maestros señalados, nos pareció ser necessario pedir ayuda de Castilla al P. Francisco, el qual nos auia prometido que nos ayudaría com alguna buena cosa (...)"

(MHSI, Epistolae mixtae, Tomo IV, pp. 775-776).

Em 1556, encontramos referência à sua actividade pedagógica em Coimbra, numa carta de Francisco Monclaro, datada de Setembro, dando conta do que se passava no colégio dessa cidade, no habitual relatório quadrimestral a Sto Inácio: 
"Los studiantes tienen sus exerciçios acustumbrados, que hazen com mucha satisfacion de sus maestros y de todos: ay entrellos muchas disputaciones, en prosa y uerso, y muchas publice, juntos los cursos com las demas classes, que es un buen auditorio; estas orationes se hazen en loor de las fiestas de nuestro Señor y de nuestra Señora, y mártires, y Santos otros. Ansí en esto como en los themas de sus maestros se haze mucho prouecho, porque á bueltas del gusto del latin gustan las cosas de Dios; porque todos sus exercicios lleuan estas suaues medicinas: ellos se huelgan mucho com ellas y añaden otras de su cabeça: ellos están ya en esto com tanto asiento, que es para loar al Señor. Ándase aora aparejando para los principios com enigmas y orationes, y un diálogo que haze el P. Pedro Perpiñan, y espérase ser estos principios muy buenos á gloria del Señor.”

(MHSI, Litterae Quadrimestres, Tomo IV, p. 532)

O ano de 1560 passa-o Perpinhão já no Colégio de Évora, na qualidade de prefeito de estudos, cursando teologia, segundo informação de Francisco Rodrigues. $^{8}$

Em Junho de 1561, o P. Jerónimo Nadal, que tinha sido enviado à Península, com poderes de decidir o que quer que fosse do interesse da Companhia, em carta a Laynez, Prepósito Geral da Companhia, escrita de Coimbra, dava conta da sua intenção de levar daí consigo Pedro Perpinhão, para servir os interesses da Companhia noutras paragens:

"De los subiectos estoy ya determinado de embiar los que pudiere por este año, y creo dentro de 4 ó cinco días partirá de aquí el P. Pedro Perpiñán, rhetórico, y insigne, y lleuará mis cartas para Salamanca y los otros collegios de Castilla, para lleuar algunos; y he scripto al prouincial de Aragón que vea si puede embiar hasta tres que no hagan falta notable, y sean aptos para leer rhetórica, ó griego, ó artes, ó theología. (...) De Portugal no se puede sacar ninguno, sino los que aquí no pueden más seruir, ni son buenos para las Indias, y ansí pienso que el año que viene podrá yr Vanegas, que es muy buen rhetórico y poeta."

(MHSI, Epistolae P. Nadal, Tomo I, pp. 491-92)

${ }^{8}$ A formação intelectual do Jesuíta. (1917) Porto: Livraria Magalhães e Moniz, 184. Baseia esta sua afirmação na correspondência dos padres Nadal e Laynez: MHSI, Epist. Nadal, I, 148 e Mon. Lainii, V, 218, VI, 66, 148. 
O seu destino foi Roma, como revela a carta de Alfonso Salmeron para Jerónimo Nadal, escrita desta cidade a 28 de Setembro de 1561:

"Después á los 20 del presente, com el P. Pedro Perpiñan y compañeros que V. R. le ordenó truxese consigo, que todos llegaron buenos y lo están, aunque Mariana se halla algo indispuesto, se há recibido outra de 21 de Junio de pocos renglones, y outra antes, de 12 de Julio, con otra de un Padre para Francisco Adorno."

(MHSI, Epistolae P. Nadal, Tomo I, p. 526)

Chegaram a Roma em 21 de Setembro de 1561. Sobre a viagem de Coimbra até ao destino escreve pormenorizadamente Perpinhão numa carta enviada, assim que ali chegou, aos companheiros de Coimbra, que se manteve desconhecida até ser publicada por Gaudeau (op. cit., pp. 149167), em 1891, e que se encontrava num manuscrito da Biblioteca Pública de Évora, intitulado Libro de las cartas de edificacion que se hallaron de Roma y de algunas otras partes mas notables, de Padres de la Compañia, y personas fuera della, que dan noticia de su buen principio y felice progresso que comiença del año de 1541, hasta el de 1569 inclusive. $F^{o}$ 342-353: copia d'una del P.e Pero Perpiñan, de Roma para los padres y hermanos de Coimbra, de 27 de setiembre de 1561. Por ela, pode estabelecer-se o exacto percurso seguido (principalmente a partir de Alcalá, pois o de Coimbra até ali fora objecto de outra carta, desta feita para os irmãos de Alcalá), a saber, Coimbra, Salamanca, Ávila, Alcalá, Guadalajara, Medina Coeli, Arcos, Saragoça, Fraga, Barcelona, Salses, Narbona, Monpeller, Nimes, Avinhão, Bolonha, Florença, Siena e Roma; nela se revelam os companheiros de viagem (Diego da Costa, vindo de Salamanca, Diego Paez, de Valladolid, P.e Ramiro, vindo de Ávila, Juan de Mariana de Alcalá, e Hieronimo Ros, de Barcelona), bem como as peripécias e acidentes de percurso, nomeadamente a passagem por lugares perigosos, pela existência de salteadores ou de hereges.

Chegou a Roma, com os companheiros, e os quatro anos seguintes passou-os no Colégio Romano, desempenhando as funções de tradutor das cartas provenientes dos missionários da Índia, professor e orador.

Em 1565, por decisão de Francisco de Borja, é destacado para França, primeiro para Lyon, depois para Paris, com o fim de, com os seus discursos, combater as teorias protestantes muito florescentes nessas regiões. 
Em consequência da sua fragilidade em termos de saúde, agravada pelos jejuns e o trabalho intenso, cai frequentemente doente, como refere em muitas das suas cartas, queixando-se aos amigos ou ao irmão ${ }^{9}$ e, em 1566, adoeceu de forma tão grave que acabou por morrer, aos 36 anos de idade, em Paris.

Era grande a sua modéstia e a sua humildade, como se revela nas suas orações e cartas aos amigos. Foi estimado e apreciado pelos seus pares, fossem ou não da Companhia. Sempre obediente, perinde ac cadauer, como postulavam as regras da Companhia, seguindo sempre religiosamente as instruções dos seus superiores, ia muitas vezes para onde não tinha desejado ir, como por exemplo para França, cujo clima e agitação religiosa receava e onde viveu cheio de saudades de Roma e dos amigos que por lá deixara, ansioso por ser mandado para Espanha ${ }^{10}$ para se restabelecer das suas doenças.

Fisicamente aparentava, além das marcas das constantes vigílias e jejuns e do trabalho contínuo, uma velhice prematura, de barba e cabelo embranquecidos muito antes do tempo, como diz Sachino:

${ }^{9}$ Das suas indisposições fala, nas cartas ao irmão, revelando a sua posição paciente face à morte. Veja-se esta, transcrita em Gaudeau 1891: 171, quando se refere à doença da mãe:

"De las indisposiciones de la Señora madre no me maravillo, pues me veo yó que soy su hijo, tan cercado dellas, aunque este año mejor he estado harto que el passado, loores á dios. Diga V. m. á la Señora de mi parte que los trabajos de la vejez e indisposiciones corporales son mensajeros de la muerte; que es menester vivir como personas que esperan cada dia outra vida mejor que esta; lo mismo digo á las Señoras nuestras tias, y al Señor tio Luis Perpinan, á los quales beso las manos y ruego me encomienden á nuestro Señor en sus oraciones. “

${ }^{10}$ Numa carta de 21 de Outubro de 1566, para Francisco de Borja, já então Prepósito Geral da Companhia, Oliverio Manareu, responsável pelo Colégio de Paris, informa:

Scrissi a V. P. che noi haveamo duoi enfermi. M $^{\text {o }}$ Perpiniano et il fratello nostro Giacomo Largiler, venuto qua da Mauriacho il giugno passato per sue indisposizioni. $\mathbf{M}^{\circ}$ Perpiniano hieri piglió l'ultima medicina et pensiamo che domani habbia de levarsi. Egli peró si persuade che questa aria gli sai poco salubre et che habbia bisogna di tornarsene in Spagna per ritrovarsi da queste sue indisposizioni; et cosi pensa far con la buona grazia di V. P. l'aprile che viene; ma ce sará tempo di mezzo per cognoscere se egli truoverá qui cagione di restare... (transcrita em Gaudeau 1891: 203). 
(...) a sua face era bela e, como se a natureza se apressasse a espalhar a majestade da velhice sobre a flor da juventude, a barba e o cabelo eram precocemente brancos. ${ }^{11}$

(aduzido por Lazeri 1749: 54)

\section{2 - A obra composta em Portugal ou relacionada com assuntos portugueses}

\section{1 - De Societatis Iesu gymnasiis et de eius docendi ratione}

Fundado em 1548 para renovar os estudos médios em Portugal, por iniciativa de D. João III, o Colégio das Artes, em Coimbra, depois de alguns anos de grande instabilidade, foi entregue, por decisão régia, à Companhia de Jesus, que tinha grande aceitação em Portugal, nomeadamente junto da Rainha e dos Infantes, pelo seu papel quer no ensino, quer nas missões (sobre este processo, veja-se a carta que escreve Diogo de Mirão a Inácio de Loyola, enviada de Lisboa em Maio de 1555 - MHSI, Epistolae Mixtae, tomo IV, fasc. V, $\mathrm{n}^{\circ}$ 955).

No dia 1 de Outubro de 1555, o Colégio foi oficialmente entregue ao padres e, nesse dia que coincidia com a abertura do ano lectivo, Pedro Perpinhão disse a oração de sapiência, que em grande parte das edições impressas recebeu o título de De Societatis Iesu gymnasiis et de eius docendi ratione, mas que, no manuscrito 3308 das B.N.L. recebeu o título de De causis cur Societas IESU collegia publica suscipiat, Rexque Lusitaniae inuictissimus Ioannes tertius conimbricense collegium illi tradiderit, et de eius docendi ratione oratio, que resume os três tópicos fundamentais desenvolvidos na oração: esclarecer os objectivos que levaram a Companhia a tomar a responsabilidade do Colégio das Artes e a dedicar-se ao ensino; os motivos que levaram o rei a entregá-lo à Companhia; a orientação a seguir com os alunos, um pequeno esboço de "ratio studiorum". Esclarecendo estas questões, justificava perante a cidade de Coimbra a sua dedicação ao ensino e ao Colégio das Artes.

O próprio Diogo Mirão, provincial da Companhia em Portugal, faz a descrição da sessão inaugural do ano lectivo de $1555^{12}$, em carta enviada a Inácio de Loyola, em 15 de Outubro de 1555:

${ }^{11}$ (...) species erat decora, et tamquam flori iuuentae senilem inspergere maiestatem natura festinasset, barba et capillus praecanus.

${ }^{12}$ Curiosamente, a Universidade teve também a sua oração de sapiência 
"El primero día de Octubre nos entregó el collegio el principal passado por mandado de el rey, conforme á lo que antes estaua concertado, y en el mesmo día á la tarde, por principio de nuestras lectiones, hizo una oración el P. Pedro Perpiñán, á lo qual combidamos toda la vniversidad, y doctores, y religiones, y á la ciudad, y á todos los demás caualleros que pudimos: y también el obispo de Coimbra se halló presente com nuestro patriharca, que tenemos agora aquá. De manera que fué de los mayores concursos y auditorios que hasta ahora uvo en esta vniversidad; y para este effecto concertamos con tapiçería vna casa muy grande, que está en este edeficio del rey, y la enramamos y hinchimos de bancos para se poder assentar todo el auditorio: y siendo la casa muy grande, aun no cabían. Empeçó la oración después de las tres, y acabó á las cinquo: de manera que duraria poco menos de dos horas. Y con esto contentó tanto, que aun quiseran que fuera más larga. Y dezía el obispo de Coimbra, que le pesaua porque acabó tan presto, y que no era possible sino que aquel hombre auía aprendido latín desde la teta de su madre, que se lo enseñase. El y todo[s] los que estauan presentes estauan attónitos y spantados, diciendo que en toda su vida no auían visto oración tan bien hecha. Unos le loauan de felicíssima memoria, porque ny erró ni titubéo en palaura ninguna hasta el cabo: otros le alabauan de pronunciación y actión, que la tuuo en stremo muy buena: otros de las cosas que dixo, que fué declarar la intención del rey e nuestra en esta mudança de entregarnos el collegio y nosotros recebirle, y quán necessaria era la virtud com las letras. Finalmente fué tanto, que muchos nos rogauan la hiziéssemos imprimir: y á todos contentó también en stremo su stilo: y así, gracias al Señor, quedaron los studiantes tan contentos y animados, que paresce no deseauan outra cosa, sino oyr los maestros de la Compañia."

(MHSI, Epistolae Mixtae, Tomo IV, pp. 27-28

\section{2 - Laudatio funebris Ludouici Principis.}

Estaé a terceira oração, de que temos conhecimento, dita publicamente em Portugal por Perpinhão. Motivou-a a morte do Infante D. Luís, em 27 de Novembro de 1555, e foi pronunciada em Dezembro desse mesmo ano; ainda recentemente, a 1 de Outubro, como vimos, dissera, no Colégio das Artes, a oração de abertura do ano lectivo.

Ela é, como qualquer outro documento fúnebre do mesmo género, uma oração com um tom grandemente laudativo e hiperbólico. Perpinhão

nesse mesmo dia 1 de Outubro, da responsabilidade de António Pinto. 
enumera, louva e exagera as qualidades de D. Luís, irmão do rei e grande amigo da Companhia e omite as suas falhas.

A oração teve lugar no Colégio das Artes e o cenário era bem outro relativamente à oração de Outubro, como diz o próprio Perpinhão: se, então, as paredes estavam cobertas de tapeçarias e de poesia e textos em prosa afixados, com uma aparência festiva, agora, estavam nuas e tristes, ornadas apenas com epitáfios.

\section{3 - Laudationis in Beatam Elisabetham Lusitaniae Reginam libri tres}

D. João III instituiu a prática de comemorar o dia 4 de Julho, dia do passamento da Rainha Santa Isabel, com uma oração no Colégio das Artes, e enviou uma carta expondo essa determinação, com data de Setembro de 1556:

Para o padre reitor do collegio das Artes em cada um anno, no dia em que se celebra a festa da rainha sancta, mandar um dos lentes fazer uma oração em louvor da sancta

"Padre reitor do collegio das Artes da cidade de Coimbra, eu el-rei vos envio muito saudar. Encommendo-vos que ordeneis que daqui em deante, em cada um anno, no dia em que se celebra a festa da rainha sancta, nessa cidade, haja uma oração publica nesse collegio, a qual dirá um dos lentes delle em louvor da dicta rainha sancta, e se fará nella menção da graça, que eu alcancei do sancto padre, para se fazer della em todos meus reinos e senhorios, e para poder haver altar e imagem della. E eu escrevo e mando ao reitor e Universidade, que no tal dia estejam presentes á dicta oração; e esta minha carta mandareis registar no livro, em que se registam as minhas provisões, para se saber como o assim tenho mandado, e se cumprir inteiramente. Jorge da Costa a fez em Lisboa a 9 dias de setembro 1556. Manuel da Costa a fez escrever. Rei"

E o padre doutor Torres, provincial, mandou que aos 4 de julho de cada anno, em que se celebra a festa da rainha sancta, se façam no collegio orações, assim em verso como em prosa, a louvor da dicta rainha sancta e del-rei D. Dinis, seu marido, e que isto se escrevesse no livro do registo, para que ficasse por memoria.

(António José Teixeira, Documentos para a história dos Jesuitas em Portugal, pp. 398-99) 
O primeiro orador escolhido para os três primeiros anos, 1557, 1558 e 1559, foi Pedro Perpinhão, como ele próprio diz, no final da monografia que compôs sobre a vida da rainha Santa Isabel:

Recebida esta carta do Rei, o Reitor impôs-me a mim primeiro a tarefa de ornar por palavras a vida da Rainha, suficientemente ilustre por si, é verdade, mas, nalguns aspectos, (...) desconhecida dos homens. E eu, aceite a tarefa, aterrorizado com a quantidade e grandeza dos feitos, propus-me, naquele primeiro ano, abordar apenas quanto considerava poder dizerse numa não muito longa oração, expondo mais do que ornando; as duas partes restantes reservei-as para os anos seguintes, bem como muitos epigramas e ainda muitas composições da mesma natureza, compostas para ela, que começaram a ser afixadas em público, como também agora vemos fazer-se todos os anos. Inflamaram-se ainda mais os espíritos dos cidadãos e dos peregrinos no amor à Rainha, não graças à nossa eloquência, que é mediana, mas ao conhecimento daquelas situações que, antes, estavam escondidas nas trevas do esquecimento. ${ }^{13}$

A instituição régia é também referida por João Afonso de Polanco, no seu Chronicon Societatis Iesu (3089), o qual acrescenta informação sobre o sucesso obtido pelo orador, que desempenhou a sua função cum summa approbatione et applausu auditorum, junto dos maiores conhecedores, harengando durante duas horas.

Foi, pois, Perpinhão, o orador escolhido, pelos seus superiores e pares, para esta tarefa inaugural de concretizar a vontade régia nos três primeiros anos, depois que D. João III estabelecera a obrigatoriedade de se celebrar

${ }^{13}$ His a Rege literis acceptis (scilicet, a carta acima transcrita dirigida ao reitor do Colégio) Rector mihi primum negotium imposuit, ut Reginam uitam, satis per se illustrem, sed (...) hominum obscuratam quadam ex parte, uerbis ornarem. Qui, prouincia suscepta, multitudine rerum et magnitudine deterritus, tantum mihi primo illo anno tractandum proposui, quantum percensendo magis quam ornando non longissima oratione dici posse confidebam; reliquas duas partes in annos consequentes reseruaui; multa quoque epigrammata, multa cujusque modi carmina in eam composita in publico figi coepta; ut etiam nunc quotannis fieri videmus. Inflammati sunt itaque magis et ciuium et peregrinorum animi studio Reginae, non eloquentia nostra, quae modica est, sed earum rerum cognitione, quae tenebris antea obliuionis inuolutae latebant.(De Vita B. Elisabethae liber tertius, pp. 383-84) 
desta forma, no Colégio das Artes, com discursos e poemas, o aniversário de Santa Isabel. Esta escolha revela a importância em que era tido, como orador e latinista, quando andava nos 27 anos de idade.

Depois de escritas e ditas as orações em louvor de D. Isabel, cujo conteúdo se encontra dividido de acordo com aqueles que Perpinhão considera os quatro grandes momentos da vida da rainha (infância e casamento são abordados na primeira oração; período da viuvez, na segunda; morte, na terceira), decide o autor registar numa monografia a vida e os feitos daquela sobre quem trabalhara nos últimos tempos; surge, então, De Vita et Moribus B. Elisabethae Lusitaniae Reginae libri III, redigida provavelmente em finais de 1559 ou em 1560.

\section{4 - De uita et moribus Diuae Elisabethae Lusitaniae Reginae libri tres}

Esta monografia apresenta, como fio condutor, o mesmo relato biográfico que existia na biblioteca do mosteiro, manuscrito e de autor anónimo, que Perpinhão já tinha utilizado para as orações, e segue a mesma ordenação das matérias, mas acrescenta-lhe mais informação, nomeadamente sobre a família da Rainha e sobre os vários conflitos em que ela interveio como pacificadora, recolhida noutras fontes adicionais, o que não pudera fazer nas orações, que tinham um objectivo diferente e um limite imposto pelo tempo e pela capacidade de atenção dos auditores.

As razões que o levaram a compor a monografia, para a qual já teria coligido alguns materiais, que lhe tinham sido necessários para as orações de 1557, 58 e 59, apresenta-as logo no início da Vita:

Por isso, hei-de falar diligentemente da vida e dos santíssimos costumes de Isabel, rainha da Lusitânia? Com efeito, foi ela que considerei, por muitos e justos motivos, dever escolher, acima de todas. Em primeiro lugar, porque, se em tamanha multidão de homens santos que floresceram na santidade de vida e de costumes, entre as nações estrangeiras, temos os feitos de pouquíssimos, e, mesmo assim, muito pouco numerosos, dos Hispânicos, então, que não se distinguiram menos, muitos deles, em religiosidade, mal conseguimos dizer os próprios nomes. Acreditei vir a aumentar, entre os homens, e não medianamente, a glória da vontade divina, se se espalhasse (se é que o posso concretizar com a debilidade deste discurso) a excelente virtude e integridade que, por tantos anos, ficaram confinadas não só às fronteiras de uma só cidade, mas até à estreiteza de uma só casa, e se se disseminasse para a memória sempiterna do orbe terrestre. 
Acrescente-se que este labor se deve aos méritos de seu avô, excelente varão, que libertou a minha pátria de infelicíssima opressão dos Sarracenos. E, na verdade, nem a João III, rei da Lusitânia já falecido, pelos tão grandes beneficios com que dotou esta nossa Companhia, podemos mostrar o agradecimento, de outra forma melhor do que esta: mostrarmos aos vindouros a memória dos feitos daquela por quem ele mostrou tanto zelo, enquanto viveu.

Finalmente o nosso amor em relação à Universidade de Coimbra parece de algum modo exigir que, na medida em que o pudermos fazer, ornemos com as nossas palavras, aquela cujo marido, Dinis, foi o primeiro dos reis da Lusitânia a iniciar a recondução à pátria das Musas exiladas, e que escolheu para elas, como domicílio agradabílissimo, esta cidade, única entre todas.. ${ }^{14}$

\section{5 - De ratione liberorum instituendorum litteris Graecis et Latinis siue, Epistola Petri Perpiniani ad Franciscum Adornum \\ Esta carta de Perpinhão a Francisco Adorno, de 1565, redigida em Roma, além de indicações biográficas, contém um importante opúsculo, no qual o autor descreve o método e os programas dos jesuítas no Colégio das}

${ }^{14}$ Igitur de uita sanctissimisque moribus Elisabethae Lusitaniae Reginae diligenter expediam? Hanc enim mihi potissimum eligendam esse duxi multis et iustissimis de causis. Nam primum cum ex tanta multitudine diuinorum hominum, qui apud exteras nationes uitae sanctitate floruerunt, paucissimorum facta, et quidem parum multa teneamus, Hispanorum autem qui non minus multi religione praestiterunt, uix nomina ipsa edere possimus, non mediocriter numinis diuini gloriam apud homines amplificatum iricredidi, si praecellens uirtus et integritas, quae tam multos annos non solum unius oppidi finibus, sed etiam unius tecti angustiis inclusa latuisset, spargeretur (si quid hac orationis tenuitate possem efficere) ac disseminaretur in orbis terrae memoriam sempiternam. Accedit quod hic labor aui eius summi uiri meritis debetur, qui patriam meam misserima Saracenorum dominatione liberauit. Neque uero Ioanni tertio Lusitaniae Regi mortuo pro maximis beneficiis, quibus nostram hanc Societatem ornauit, alia ratione melius gratiam aliquam possumus referre, quam si posteris prodamus factorum eius memoriam, cuius ille fuit studiosissimis dum vixit; et noster amor aduersus Conimbricensem Academiam postulare quodammodo uidetur, ut eam, quoad fecere possimus, uerbis ornemus, cuius uir Dionysius primus Lusitaniae Regum, aggressus exulantes Musas reducere in patriam, hanc eis urbem unam ex omnibus sedem gratissimam delegit.

(Liber Primus, pp.167-168) 
Artes, enquanto ali viveu e trabalhou. Essa descrição fora-lhe solicitada pelo amigo e antigo companheiro de Coimbra nesse momento secretário do Cardeal Carlos Borromeu, sobrinho do Papa, tendo em vista já o objectivo da Companhia de reunir um conjunto de estudos que reflectiam as práticas pedagógicas dos seus vários colégios, para as sistematizar, como viria a acontecer com a elaboração da Ratio Studiorum, alguns anos mais tarde. Francisco Adorno viria a fazer parte da equipa responsável por redigir este documento ${ }^{15}$.

\section{6-Poesia}

Também à poesia se dedicou Perpinhão, como todo o latinista que se prezava; neste campo, temos a destacar os pequenos poemas fúnebres de Santa Isabel e D. João III, além de uma écloga. Os primeiros, recolhidos num manuscrito existente na Biblioteca Nacional de Lisboa ${ }^{16}$, poderão ter estado, como exercícios literários compostos para esse efeito, afixados no átrio e salas do Colégio, por ocasião das datas fúnebres ou festivas (como

${ }^{15}$ François Dainville (1940), La Naissance de l'Humanisme moderne, Paris: Beauchesne et ses Fils, Éditeurs, 78, estabelece a relação entre o texto de Perpinhão e o Ratio Studiorum, bem como entre o método dos jesuítas e o de Bordéus e de Coimbra:

Signalons parmi les sources certaines du Ratio, une lettre trop peu connue, adressée par le p. Perpinien au P. Adorno, le 20 janvier 1565 (Epistolae, ep. XVI, p. 86-110). Comme nous aurons l'occasion de l'indiquer dans les notes du chapitre suivant, des passages entiers de ce précieux document ont été repris presque à la lettre par les rédacteurs du Ratio. Il éclaire, en outre, à notre avis, la question si délicate des emprunts possibles, par les Jésuites, de telle ou telle institution du Collège de Guyenne. Perpinien nous prévient, en effet, que son exposé décrit les méthodes qui se pratiquent avec succès au Collège de Coimbre.

${ }^{16}$ O Códice 3308 intitula-se Rerum scholasticarum, quae a patribus, ac fratribus huius Conimbricensis Collegii scriptae sunt. Tomus primus. Abrange um grande conjunto de composições dos jesuítas, em prosa e em verso, respeitante aos anos que vão de 1555 a 1572 . Nela se encontram todas as orações de Perpinhão ditas em Portugal, acima citadas, alguns exemplares da sua veia poética e um diálogo que terá sido representado a um de Setembro de 1556. Para mais informação vd. Sebastião Tavares de Pinho, (1991), "Literatura humanística inédita do Colégio das Artes da Universidade de Coimbra no Século XVI", Universidades, História, Memória, Perspectivas. Actas do Congresso "História da Universidade (no $7^{\circ}$ Centenário da sua Fundação)”, 4 , Coimbra. 
a morte de D. João III, ou a comemoração do dia da Rainha Santa), juntamente com muitos outros textos, em prosa ou em verso, de outros professores e de alunos. As circunstâncias da composição do outro texto referido, a Ecgloga Melibaeus que, desde o título, apresenta nítidas influências das Bucólicas de Virgílio, descreve-as o autor na carta escrita aos companheiros de Coimbra (Gaudeau 1891: 165-167), após a sua viagem até Roma, quando, em 1561, para ali o mandou a Companhia:

El sábado a la tarde y el domingo de mañana, vine muy poetico por el camino, ordenando una Egloga que despues escrivi, y la embiaré al pié desta carta, para que dé testimonio del amor que siempre yo a todos tuve y tengo en el Señor Nuestro; aunque no fué remirada por nueve años, ni va tan limada como la erudicion desse collegio requeria, recibanla con la affecion con que se les embio.

\section{7 - Megalopragmon siue ambulatio pomeridiana}

O diálogo de Perpinhão foi escrito em 1556, para o dia 1 de Setembro (segundo indicação existente no próprio códice em que se transcreve o texto), e apenas conhecemos um texto manuscrito, no Códice 3308 da Biblioteca Nacional de Lisboa, proveniente do Colégio das Artes de Coimbra, que contém a produção oratória, poética e dramática dos padres, entre os anos 1555 e 1572; esse diálogo está, em grande parte, ilegível.

Não conhecemos qualquer texto impresso deste diálogo. É natural que não tenha sido publicado, em obediência a uma norma enviada aos colégios, de acordo com a qual não se deviam publicar esses textos, mas apenas transcrevê-los para uso interno. (vd. MHSI, Monumenta Ignatiana, vol. VI, ep. $n^{\circ} 4149$, p. 119)

A carta quadrimestral de Setembro de $1556^{17}$ dá a indicação de que o autor andava a preparar o diálogo; o códice da B.N.L., porém, indica a data do dia 1 de Setembro, logo abaixo do título. É natural que tenha sido representado durante alguma celebração académica, alguma entrega de prémios, ou na preparação do início do ano lectivo. Tal como os professores que os tinham antecedido no Colégio das Artes se tinham dedicado à composição dramática, como Buchanan e Diogo de Teive, também os jesuítas a incentivaram, como auxiliar da sua pedagogia, revelando pre-

${ }^{17}$ MHSI, Litterae Quadrimestres, tomo IV, pág. 532. 
ferência por temas bíblicos ou de conteúdo relacionado com a prática e a moral cristãs ${ }^{18}$.

Enquanto viveu em Portugal, Pedro Perpinhão desenvolveu intensa actividade de orador, professor e investigador, deixando produção literária relevante, que seria posteriormente objecto de variadas edições. Coube-lhe o papel de ter iniciado e engrandecido as celebrações académicas da Rainha Santa, no Colégio das Artes, bem como o de, nesta instituição, ter proferido a lição inaugural, com a qual se justificava, perante a cidade de Coimbra, a entrega do Colégio à Companhia de Jesus e se revelavam os seus princípios orientadores.

\section{Bibliografia}

Códice 3308 da Biblioteca Nacional de Lisboa: Rerum scholasticarum quae a patribus ac fratribus huius Conimbricensis Collegii scripta sunt tomus primus.

Códice 993 da Biblioteca Geral da Universidade de Coimbra, Rerum scholasticarum quae a patribus ac fratribus huius Conimbricensis Collegii scripta sunt tomus secundus.

Gaudeau, P. B., SJ (1891), De Petri Ioannis Perpiniani uita et operibus (1530-1566). Parisiis: apud Retaux-Bray Editorem.

Lazeri, R. (1749), Petri Ioannis Perpiniani Valentini e Societate Iesu Opera.(3 vols.), Romae, Typis Nicolai et Marci Palearini.

----------- (1749), De Vita et Scriptis Petri Ioannis Perpiniani Diatriba. Romae: Typis Nicolai et Marci Palearini.

Monumenta Historica Societatis Iesu a Patribus Eiusdem Societatis edita:

Polanco, João Afonso, Chronicon Societatis Iesu, Madrid, 1894-1898, 6 vols.

Litterae Quadrimestres ex uniuersis praeter Indiam et Brasiliam locis, in quibus aliqui de Societate Iesu uersabantur, Romam missae. Madrid, 1894-1925, 6 vols.

Epistolae Mixtae ex uariis Europae locis ab anno 1537 ad 1556 scriptae. Madrid, 1898-1901. 5 vols.

${ }^{18}$ Sobre o teatro neo-latino escolar, leia-se Claude-Henri Frèches (1964), Le théatre neo-latin au Portugal (1550-1745), Paris, Lisbonne. 
Epistolae P. Hieronymi Nadal Societatis Iesu ab anno 1547 ad 1577. Madrid, 1898-1905, 4 vols.

Perpiniani, P. I. (1749), Opera (3 vols.). Romae: Typis Nicolae, et Marci Palearini.

Teixeira, A. J. (1899), Documentos para a História dos Jesuitas em Portugal. Coimbra.

Telles, B. (1645-1647), Chronica da Companhia de Jesus na Provincia de Portugal (2 vols). Lisboa. 